\title{
Adsorption Study of Utilizing Calabash (crescentia cujete) Seed in the Removal of Heavy Metals from Industrial Wastewater
}

\author{
${ }^{1}$ AMIGUN, AT., ${ }^{2}$ JAMIU, W., ${ }^{2}$ ADEBAYO, GB., ${ }^{3} \mathrm{JIMOH}$ AA.

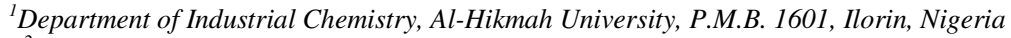 \\ ${ }^{2}$ Department of Industrial Chemistry, University of Ilorin, P.M.B. 1515, Ilorin, Nigeria \\ ${ }^{3}$ Department of Chemistry, Kwara State University, Malete, Ilorin, Nigeria \\ *Corresponding Author: waschem06@gmail.com.
}

\begin{abstract}
This work was carried out to assess the physicochemical parameters and removal of heavy metals from industrial wastewater by activated carbon prepared from calabash seed. Some physicochemical parameters of the wastewater that assessed are $\mathrm{pH}$, temperature, and turbidity, BOD, COD, TS, TDS and TSS. Adsorption studies on the effects of contact time, $\mathrm{pH}$ and adsorbent doses on the removal of heavy metals were investigated. The $\mathrm{pH}$ and temperature of granite industrial wastewater were 7.5 and 32.5 respectively which are within the permissible limit of WHO (7-8.5 and $\left.32{ }^{\circ} \mathrm{C}\right)$. The wastewater sample shows extremely high turbidity of $2.5 \mathrm{mg} / \mathrm{l}$, biochemical oxygen demand (BOD) of $430 \mathrm{mg} / \mathrm{l}$, chemical oxygen demand (COD) of $283 \mathrm{mg} / \mathrm{l}$, total solid (TS) of $45 \mathrm{mg} / \mathrm{l}$, total dissolved solid (TDS) of $655 \mathrm{mg} / \mathrm{l}$ and total suspended solid (TSS) of 965 which are above permissible limit of WHO. The maximum adsorption capacity of $\mathrm{Zn}(99 \%)$ and $\mathrm{Fe}(88 \%)$ were observed at $\mathrm{pH} 8$ and 12 respectively. The pseudo-fist order and pseudo-second order kinetic models were used to fit the kinetic data of the adsorption process, and the result obtained showed that pseudo-second order kinetic model was able to fit the generated adsorption data from the heavy metals considered in this research work due to the regression coefficient $R^{2}$ of 0.997 value obtained. The study reveals that granite industrial wastewater effluent is one of the industries responsible for polluting the surrounding aquatic environment.
\end{abstract}

DOI: https://dx.doi.org/10.4314/jasem.v22i2.11

Copyright: Copyright (c) 2018 Amigun et al. This is an open access article distributed under the Creative Commons Attribution License (CCL), which permits unrestricted use, distribution, and reproduction in any medium, provided the original work is properly cited

Dates: First received 25 July 2017; Received in revised form 29 January 2018; Accepted 10 February 2018

Key words: Kinetic study, calabash seed, adsorption, heavy metals, wastewater

Pollution by the discharge of heavy metals into the environment has become a matter of concern over the last few decades. Numerous industries such as electroplating, steel and nonferrous processes, metal finishing operations, electronic circuit production, fine-chemical and pharmaceutical production discharge a variety of toxic heavy metals into the environments (Abdus-salam and Adekola, 2005).

Several researchers have published many research works on the application of agricultural raw materials as good substrates for the removal of metal ions from aqueous solutions and wastewaters. This process attributes to the uses of waste to treat waste and become even more effective because these agricultural by-products are readily available and often pose waste disposal problems. Hence, they can be easily sourced at little or no cost because they are waste products. Also, this makes the process of remediating wastewaters with agricultural material adsorbents more economical than using conventional adsorbents like commercial activated carbon. In addition, the complicated regeneration is no need for adsorption process when using agricultural by- products for wastewater treatment (Abia and Igwe, 2005).

From several literature conducted it has reveals that no research work has reported the Physico-chemical characterization and potential of calabash (crescentia cujete) seed in the removal of $\mathrm{Fe}$ and $\mathrm{Zn}$ from industrial wastewater. Hence, the objective of this paper is to investigate and report the physicochemical properties of calabash seed and convert the seed to activated carbon for the removal of some heavy metals in industrial wastewater

\section{MATERIALS AND METHODS}

Collection and preparation of adsorbent: Calabash seed were obtained from Apalara in Ilorin West Local Government of Kwara State, Nigeria. The sample was sun dried for 7 days and crushed with a mortar and pestles, then sieved using $0.25 \mathrm{~nm}$ sieve size to reduce their sizes. About $15 \mathrm{~g}$ of the resulting powdered sample was weighed into six different clean and pre-weighed crucibles; they were then introduced into the muffle furnace (OH85TR Gallenkamp). They were carbonized at $300{ }^{\circ} \mathrm{C}$ for an 
hour. The content was then removed from the muffle furnace after the set period and cooled in an open air for one hour. This process was repeated until a substantial amount of carbonized sample was obtained. Activation of the carbonaceous material produced was carried out in accordance with the description reported by Adebayo et al. (2015).

Wastewater Collection: The wastewater effluent from $\mathrm{Sal} / \mathrm{Yemic}$ granites industrial limited located in Masaka area, Nassarawa state, Nigeria was collected in a sterile $4 \mathrm{~L}$ plastic container from its point of discharge to the environment. For preservation and pre-treatment, about $5 \mathrm{~mL}$ of $2.0 \mathrm{M}$ nitric acid was added per litre of the sample. The wastewater sample was refrigerated at approximately $4{ }^{\circ} \mathrm{C}$ to avoid heavy metal precipitation and kept for further use.

Physicochemical study: The granite wastewater sample was collected and were analyzed for, $\mathrm{pH}$, temperature, turbidity, Total Solids(TS), Total Dissolved Solids(TDS), Total Suspended Solids (TSS), Bio-chemical Oxygen Demand (BOD) and Chemical Oxygen Demand(COD) values. The analysis were carried in accordance to the reported by (Lokhande et al., 2011)

pH: The pH of the sample was taken with the aid of hand portable $\mathrm{pH}$ meter by immersing its electrode into the wastewater sample and the reading was recorded.

Temperature: The temperature of the wastewater was determined at the point of wastewater sample collection with aid of mercury thermometer (0$110^{\circ} \mathrm{C}$ ) by inserting the thermometer tip into the water sample and the re4ading was recorded.

Turbidity: About $20 \mathrm{ml}$ of the wastewater sample was measured in a beaker, and HACH turbid meter was used to measure the turbidity and the reading was taken when it is stable.

Total Dissolved Solids: A TDS meter was used to determine the total solid, and the reading was recorded.

Total Suspended Solid: A Filter paper was dried in an oven to a constant weight and allowed to cool at room temperature. A $50 \mathrm{ml}$ of wastewater sample was measured and filtered on the pre dried filter paper. The filter paper was removed gently and dried in an oven to constant weight at $10{ }^{\circ} \mathrm{C}$. It was allowed to cool and weighed, TSS was calculated by equation 1 below:
$\mathrm{TSS}=\left(\frac{W_{1}-W_{0} \times 10^{6}}{V_{S}}\right)$

Where $\mathrm{W}_{1}$ is the weight of filter paper + residue and $\mathrm{W}_{\mathrm{o}}$ is the weight of filter paper

Total solid: A total solid was determined by addition of total dissolved solids and total suspended solids.

$\mathrm{TS}=\mathrm{TDS}+\mathrm{TSS}$

Biochemical Oxygen Demand (BOD): The iodometric titration method was used. A $20 \mathrm{ml}$ of wastewater sample was measured in reagent bottle; about $5 \mathrm{ml}$ of $10 \% \mathrm{MnCl}_{2}$ was added and $5 \mathrm{ml}$ of alkaline iodine solution. The bottle was corked and shaken well. A $10 \mathrm{ml}$ of $25 \% \mathrm{HCl}$ was added and shaken. The mixture was titrated against $0.05 \mathrm{M}$ sodium thiosulphate, on appearance of pale yellow coloration, A 3 drops of starch indicator was added and titration continue to till colourless end point.

Dissolved Oxygen $=\frac{\left[8000 \times\left(V_{b}-V_{a}\right) \times C\right]}{V_{S}}$

Where $\mathrm{Va}, \mathrm{Vb}$ is the titre value for sample and blank respectively, Vs is volume of sample, therefore BOD can be calculated as:

$\mathrm{BOD}=\mathrm{DO} 1^{\text {st }}$ day $-\mathrm{DO} 7^{\text {th }}$ day

Chemical Oxygen Demand (COD): The closed reflux titrimetric method was used. A $10 \mathrm{ml}$ of wastewater effluent was measured in a beaker, about $90 \mathrm{ml}$ of distilled water, $10 \mathrm{ml}$ of $25 \% \mathrm{H}_{2} \mathrm{SO}_{4}$ and $20 \mathrm{ml}$ of $0.01 \mathrm{M} \mathrm{KMnO}_{4}$ was added. It was heated in water bath for 30 minutes and allowed to cool before adding $10 \% \mathrm{KI}$. It was titrated against $0.05 \mathrm{M}$ sodium thiosulphate until pale yellow coloration, few drops of starch indicator was then added and titrated to colourless.

$\mathrm{COD}=\frac{(A-B \times N \times 400)}{V_{S}}$
$\mathrm{Vs}=$ Volume of sample

Heavy Metal Analysis: The digestion of wastewater for heavy metal analysis was done in accordance with method reported by Gin et al., (2014). About $100 \mathrm{ml}$ of the effluent were digested using $10 \mathrm{~mL}$ triple acid mixture $\left(5: 1: 1-\mathrm{HNO}_{3}: \mathrm{HClO}_{4}: \mathrm{H}_{2} \mathrm{SO}_{4}\right)$ in a $250 \mathrm{~mL}$ conical flask placed in a fume cupboard and heated on a hot plate until the solution was reduced to 10 $\mathrm{mL}$. Thereafter, it was allowed to cool and make up to a mark with distilled water, it was then filtered into a $50 \mathrm{~mL}$ standard flask labelled and made ready for further analysis. The concentrations of the heavy 
metals in the wastewater were determined using Atomic Absorption Spectrometer (Perkin, 210 VGP).

Sorption Experiments: Batch adsorption experiments were conducted and the effects of some selected reaction parameters on the rates of metal ions uptake from the wastewater sample using the developed activated calabash seed were investigated. The parameters considered include $\mathrm{pH}$, agitation time and adsorbent dosage. These effects were carried out in accordance with the reported work of Elaigwu et al. (2009).

Effect of pH: A $25 \mathrm{ml}$ of wastewater sample were contacted with $0.2 \mathrm{~g}$ of the adsorbent in a $100 \mathrm{ml}$ conical flask and the $\mathrm{pH}$ of the mixture was adjusted with $0.1 \mathrm{M} \mathrm{HCl}$ and $0.1 \mathrm{M} \mathrm{NaOH}$ and maintained to the required value of $2,4,6,8,10$ and 12 . The solution was agitated for 2hours, filtered and the residual metal ion concentrations were analyzed using Atomic Absorption Spectrophotometer.

Effect of contact Time: A $25 \mathrm{~mL}$ of the granite wastewater was measured into a conical flasks and about $0.2 \mathrm{~g}$ of the adsorbent was weighed into a beaker and agitated for different contact time of (20, 40, 60, 80, 100 and $120 \mathrm{~min}$ ). After each agitated time, the content of the beaker was filtered, and the equilibrium concentration of each of the metals was determined by Atomic Absorption Spectrophotometer.

Effect of Adsorbent Dose: The effect of adsorbent dosage was studied by weighing $25 \mathrm{~mL}$ each of the wastewater to various amounts of the adsorbent (1.0 $3.5 \mathrm{~g}$ ) in different conical flask and agitated on a mechanical shaker for 2hours. After completion of the reaction, conical flasks were taken out and resulting mixture were filtered and analyzed using Atomic Absorption spectrophotometer.

The \% adsorbed was determined using the mass balance expression obtained from the work of Bernard et al. (2013).

$\%$ adsorbed $=\frac{\mathrm{C}_{\mathrm{o}}-\mathrm{C}_{\mathrm{f}}}{\mathrm{C}_{\mathrm{o}}} \times 100$

Where $C_{o}$ and $C_{f}$ represent the initial and final concentration of metal ions

Kinetic study profile: In kinetics profile of the activated carbon material in the adsorptive uptake of heavy metals from wastewater at different time intervals, the adsorption kinetics was studied. The pseudo-first-order and pseudo-second-order model equations are fitted to model the kinetics of heavy metals adsorption onto activated carbon. The general expression for pseudo-first-order equation model is shown in equation (7) and (8):

$\frac{d q_{t}}{d t}=k_{1}\left(q_{e}-q_{t}\right)$

Where, $\mathrm{q}_{\mathrm{e}}$ and $\mathrm{q}_{\mathrm{t}}$ are the amount of metals adsorbed at equilibrium and time $t$, respectively. $\mathrm{k}_{1}$ is the rate constant for the pseudo first order adsorption. The integrated rate law is given as follows

$\log \left(q_{e}-q t\right)=\log q_{e}-\frac{K}{2.303}$

A plot of $\log \left(q_{e}-q_{t}\right)$ against $\mathrm{t}$ was made and the values of $\mathrm{k}_{1}$ and $\mathrm{q}_{\mathrm{e}}$ were obtained from the slope and intercept, respectively.

The linear form of pseudo-second order kinetics model is given as:

$\frac{t}{q_{t}}=\frac{1}{k_{2} q_{e}^{2}}+\frac{1}{q_{e}} t$

Where, $\mathrm{q}_{\mathrm{e}}$ and $q_{t}$ are the amount of metal ion adsorbed per unit mass of the adsorbent (in $\mathrm{mg} \mathrm{g}^{-1}$ ) at equilibrium and time $t$, respectively, and $k_{2}$ is the pseudo second order rate constant. A linear plot of $\mathrm{t} / \mathrm{q}_{\mathrm{t}}$ against $t$ confirms the fitness of data to this model

\section{RESULTS AND DISCUSSION}

$\mathrm{A} \mathrm{pH}$ is a measure of the acidity or alkalinity of water and is one of the stable measurements. $\mathrm{A} \mathrm{pH}$ is a simple parameter but is extremely important, since most of the chemical reactions in aquatic environment are controlled by any change in its value. Anything either highly acidic or alkaline would kill marine life. Aquatic organisms are sensitive to $\mathrm{pH}$ changes and biological treatment requires $\mathrm{pH}$ control or monitoring. It has been reported that the toxicity of heavy metals also gets enhanced at particular $\mathrm{pH}$, which is primary importance in deciding the quality of waste water effluent. Water with $\mathrm{pH}$ value of about 10 are exceptional and may reflect contamination by strong base such as $\mathrm{NaOH}$ and $\mathrm{Ca}(\mathrm{OH})_{2}$ (Langmuir, 1997). The $\mathrm{pH}$ of wastewater sample obtained was 7.5 which are within the recommended standard limits of regulating bodies WHO (7.0-8.5), but slightly higher than the reported research elsewhere Lokhande et al., 2011 (5.2).

Temperature is one of the most important ecological features. It controls behavioural characteristics of organisms, solubility of gases and salts in water. The basis of all life functions is complicated set of 
biochemical reactions that are influenced by physical factors such as temperature. Disease resistance is also linked to temperature; increase in temperature also increases the rate of microbial activity. Temperature increase may become barrier to fish movement and with this limitation is seriously affect on reproduction of species.. In the present study, the temperature of industrial effluent obtained is $32.5^{\circ} \mathrm{C}$ which is slightly above the permissible limits.

BOD may be defined as the rate of removal of oxygen by microorganisms in aerobic degradation of the dissolved organic matter in water over a 5-days period. It has been reported that increases in BOD can be due to heavy discharge of industrial waste water effluent, animal and crop wastes and domestic sewage. BOD values have been widely adopted as a measure of pollution effect according to WHO the maximum permitted BOD content is < $100 \mathrm{mg} / \mathrm{L}$. The experimental data of present investigation shows that BOD value of $430 \mathrm{mg} / \mathrm{L}$ in wastewater effluent samples which were extremely higher than the permissible limit. It is important to note that low BOD content is an indicator of good quality water, while a high BOD indicates polluted water.

The Chemical Oxygen Demand (COD) determination is a measure of the oxygen equivalent of that portion of the organic matter in a sample that is susceptible to oxidation by a strong chemical oxidant. It is an important, rapidly measured parameter for industrial waste water studies and control of waste treatments. COD is also one of the most common measures of pollutant organic material in water. COD is similar in function to BOD, in that both measure the amount of organic compounds in water. In the present investigation the COD values is $283 \mathrm{mg} / \mathrm{L}$ in the effluent samples It was observed that the wastewater effluent values is very much higher than $5.0 \mathrm{mg} / \mathrm{L}$ which is a maximum permissible limit according to WHO Standard.

TDS content in water is a measure for salinity. A large number of salts are found dissolved in natural waters, the common ones are carbonates, bicarbonates, chlorides, sulphates, phosphates, and nitrates of calcium, magnesium, sodium, potassium, iron, and manganese, etc. Water can be classified based on the concentration of TDS (Vilcox 1995), for desirable for drinking (up to $500 \mathrm{mg} / \mathrm{L}$ ), permissible for drinking (up to $1,000 \mathrm{mg} / \mathrm{L}$ ), useful for irrigation (up to $2,000 \mathrm{mg} / \mathrm{L}$ ), not useful for drinking and irrigation (above $3,000 \mathrm{mg} / \mathrm{L}$ ). In the present investigation, the wastewater has TDS value of 45 $\mathrm{mg} / \mathrm{L}$. Based on the above classification, it was observed that industrial wastewater effluents is within the permissible limit

The wastewater effluents is also shows high TSS and TS values of $965 \mathrm{mg} / \mathrm{L}$ and $45 \mathrm{mg} / \mathrm{L}$ respectively, which are higher than the WHO permissible limits. The table below shows the concentrations of some physicochemical parameters of granite industrial wastewater

Table 1: Physico-chemical characterization of industrial waste water analyzed

\begin{tabular}{ccc}
\hline parameters & wastewater & WHO Limit \\
\hline $\mathrm{pH}$ & 7.50 & $7-8.5$ \\
Temperature $\left({ }^{0} \mathrm{C}\right)$ & 32.5 & 32 \\
Turbidity & 2.5 & 1.5 \\
$\mathrm{BOD}(\mathrm{mg} / \mathrm{l})$ & 430 & $<100$ \\
$\mathrm{COD}(\mathrm{mg} / \mathrm{l})$ & 283 & 5.0 \\
$\mathrm{TS}(\mathrm{mg} / \mathrm{l})$ & 45 & 30 \\
$\mathrm{TDS}(\mathrm{mg} / \mathrm{l})$ & 655 & 500 \\
$\mathrm{TSS}(\mathrm{mg} / \mathrm{l})$ & 965 & 500 \\
$\mathrm{Zn}(\mathrm{mg} / \mathrm{l})$ & 0.18 & $\mathrm{NI}$ \\
$\mathrm{Fe}(\mathrm{mg} / \mathrm{l})$ & 0.36 & $\mathrm{NI}$ \\
\hline WHO: World Health Organization, NI: Not Indicated
\end{tabular}

Adsorption Experiment Results: Effect of $p H$ : The initial $\mathrm{pH}$ of a solution is a very important factor to be considered in adsorption studies as it has been observed to play a major role in the adsorption of metal ions by various adsorbents, because it affects the solubility of the metal ions, concentration of the counter ions on the functional groups of the adsorbent and the degree of ionization of the adsorbate during reaction (Badmus et al., 2007).

In this study, the effect of $\mathrm{pH}$ on the $\mathrm{Fe}$ and $\mathrm{Zn}$ adsorption capacities of the adsorbent was conducted at various $\mathrm{pH}$ ranging 2-12. The role of $\mathrm{H}^{+}$ concentration was examined from the sample at different $\mathrm{pH}$. The result shows that the maximum adsorption of $\mathrm{Fe}(88 \%)$ and $\mathrm{Zn}(99 \%)$ was observed at $\mathrm{pH} 8$ and 12 respectively, while the amount adsorbed increases with increases in $\mathrm{pH}$. Similar trend were report in literature by Kobya et al., (2005).

It was observed that as the $\mathrm{pH}$ of the adsorbing medium were increased from 2-12, there was a corresponding increase in deprotonation on the adsorbent surface leading to a decrease in $\mathrm{H}^{+}$ion on the adsorbent surface (Abdus-salam and Adekola, 2005). 


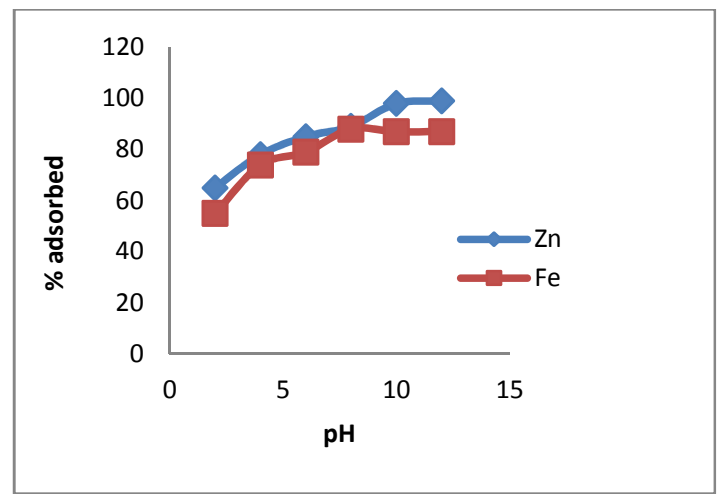

Fig 1: Effect of $\mathrm{pH}$ on adsorption of $\mathrm{Zn}$ and $\mathrm{Fe}$ onto activated carbon sample

Effect of contact Time: The adsorption of metal ions from aqueous solutions is controlled by the rate of reaction at which the equilibrium time is determined. The effects of contact time for the adsorption of $\mathrm{Zn}$ and $\mathrm{Fe}$ were studied between 20 and 120 minutes. The maximum amount adsorbed at different time differs for each metal ion. For $\mathrm{Zn}$ metal ion maximum adsorption capacity of $96 \%$ within 80 minutes of the experiment was observed; further increase in contact time had no significant effect on the adsorption capacity, The faster rate of removal of $\mathrm{Fe} 92 \%$ at 60 minutes may be due to the availability of the uncovered surface area of the adsorbents, since the adsorption kinetics depends upon the surface area of the adsorbent (Qadeer and Akhtar, 2005).

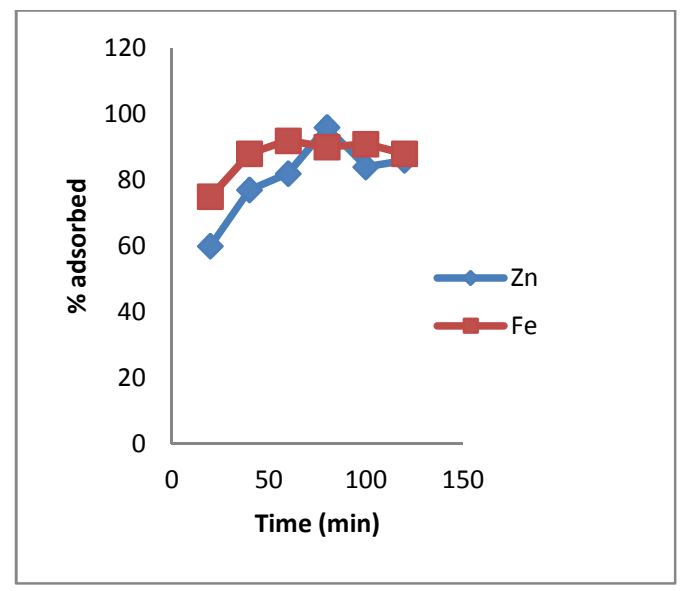

Fig 2: Effect of contact time on adsorption of $\mathrm{Zn}$ and $\mathrm{Fe}$ on to activated carbon

Effect of Adsorbent Dose: In the present study, the influence of different amounts of adsorbents dose on the uptake of $\mathrm{Zn}$ and $\mathrm{Fe}$ which varies between 1.0$3.5 \mathrm{~g}$ showed decrease in the percentage adsorbed with increase in adsorbent dosage rate. It has reported that as the number of adsorbate concentration decreases per active site, there is possibility for sorption available on the surface (Yu et al., 2000).
The Figure 3 shows the effect of adsorbent dose on adsorption of $\mathrm{Zn}$ and $\mathrm{Fe}$ and maximum adsorption was observed at $1.0 \mathrm{~g}$ of adsorbent for metals, $94 \%$ and $74 \%$. From the research work, it was observed that small amount of adsorbent gave maximum adsorption; this may be due to the high surface area and micropore volume of the activated carbon sample.

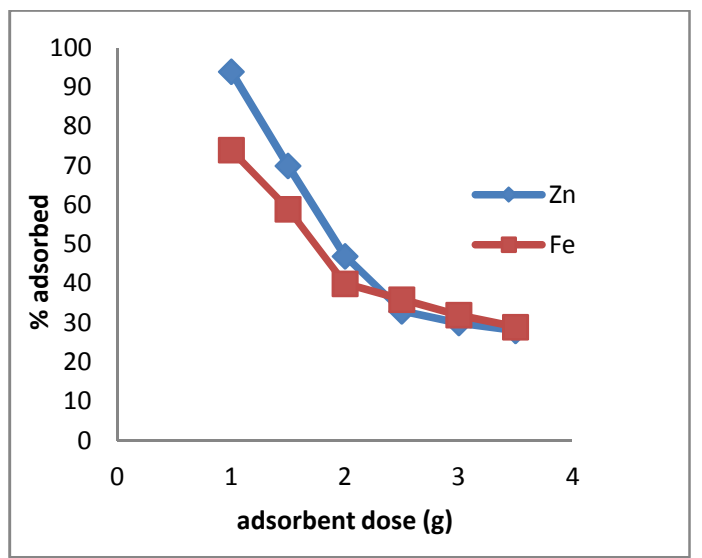

Fig 3: Effect of adsorbent dose on adsorption of $\mathrm{Zn}$ and $\mathrm{Fe}$ onto activated carbon

Adsorption Kinetics Modeling: The kinetics of an adsorption is probably the most important factor in predicting the rate at which adsorption takes place in a given reaction. It is regarded as the tool used to examine the mechanism of adsorption process such as chemical reaction and mass transfer, therefore suitable methods is needed to analyze the rate data. The Lagergren's first-order kinetic model and the Ho's pseudo-second-order model are the most frequently used in the literature to predict the mechanism involved in the sorption process (Ho and McKay, 1998). In this study we used the both kinetic models to test the adsorption kinetic of both $\mathrm{Zn}$ and Fe onto activated carbon adsorbent.

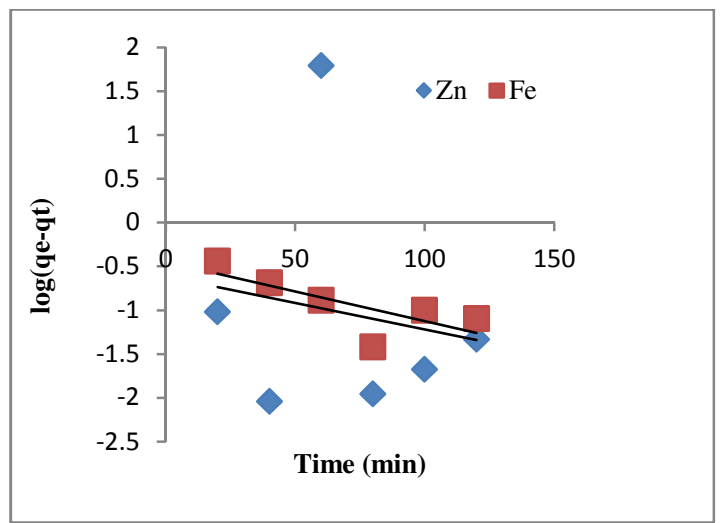

Fig 4. Pseudo-first order kinetic model for adsorption of $\mathrm{Zn}$ and Fe on activated carbon 
Table2. Estimated coefficient of empirical kinetic models for activated carbon

\begin{tabular}{ccccccc}
\hline Metals & \multicolumn{3}{c}{ Pseudo-first order } & \multicolumn{3}{c}{ Pseudo-second order } \\
\cline { 2 - 7 } & $\mathrm{K}_{1}\left(\mathrm{~min}^{-1}\right)$ & $\mathrm{qe}(\mathrm{mg} / \mathrm{g})$ & $\mathrm{R}^{2}$ & $\mathrm{~K}_{2}\left(\mathrm{~g} / \mathrm{mgmin}^{-1}\right)$ & $\mathrm{qe}(\mathrm{mg} / \mathrm{g})$ & $\mathrm{R}^{2}$ \\
$\mathbf{Z n}$ & 0.008 & 0.378 & 0.006 & 0.555 & 0.121 & 0.951 \\
$\mathbf{F e}$ & 0.006 & 0.703 & 0.528 & 0.086 & 1.846 & 0.997 \\
\hline
\end{tabular}

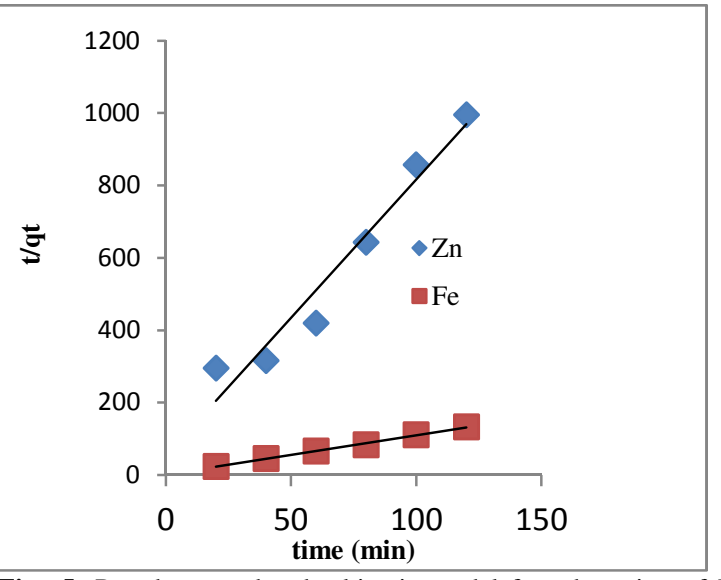

Fig 5: Pseudo-second order kinetic model for adsorption of $\mathrm{Zn}$ and $\mathrm{Fe}$ on activated carbon

Both models were examined for suitability using their correlation coefficient $\mathrm{R}^{2}$. Comparison of the two models, it was revealed that the adsorption of the metals could best explain using the pseudo-second order. This was due to the higher correlation regression coefficient $R^{2}(0.997)$ value. It was observed from the figure 4 and 5 below that correlation regression coefficient of the sample for the second order were greater than the first order, this trend was the same as reported by Idris et al., (2012).

Conclusion: Generally, all countries in the world are struggling to arrive at effective regulatory guidelines to control the discharge of industrial effluents into their various ecosystems. The present experimental data indicates high level of pollution that occurs through the discharge of granite industrial effluent in to the water body. Therefore, from the experimental results from above studies shows that activated carbon form calabash seed is an inexpensive and reliable material for the removal of toxic metals from the wastewater.

\section{REFERENCES}

Abdus-Salam, N; Adekola, FA (2005) "The influence of $\mathrm{pH}$ and adsorbent concentration on Adsorption of Lead and zinc on a Natural Goethite" AJST 6; 55-56.

Abia, AA; Igwe, JC (2005). Sorption Kinetics and Intraparticulate diffusivities of $\mathrm{Cd}, \mathrm{Pb}$, and $\mathrm{Zn}$ ions on Maize Cob, J. of Biotech. 4(6): 509-512
Adebayo, GB; Adegoke, HI; Jamiu, W; Balogun, BB; Jimoh AA (2015). Adsorption of $\mathrm{Mn}(\mathrm{II})$ and $\mathrm{Co}(\mathrm{II})$ ions from aqueous solution using Maize cob activated carbon: Kineticsand Thermodynamics Studies. J. Appl. Sci. Environ. Manage. 19(4): 737-748.

Badmus, MAO; Audu, TOK; Anyata, BU (2007). Removal of Lead ion from Industrial Waste water by Activated carbon from Periwinkle shells. Turkish J. Env. Sci. 31: 251-263.

Elaigwu, SE; Usman, LA; Awolola, GV; Adebayo, GB; Ajayi, RMK (2009).Adsorption of pb (II) from aqueous solution by activated carbon prepared from cow dung. Adv. Nat. Appl. Sci. 3(3): 442-446.

Yu, ZY; Shukla, A; Doris, KL (2000). The removal of heavy metal from aqueous solutions by saw dust adsorption. J. Haz Mat. 80:33-42.

Ho, YS; Mckay, G (1998). A Comparsion of Chemisorption Kinetic, Model Applied to Pollutant removal on various sorbents. J. of Inst. Chem. Eng. 76(17): 332-340.

Idris, S; Iyaka, YA; Dauda, BEN; Ndamitso, MM; Umar, MT (2012). Kinetic Study of Utilizing Groundnut Shell as an Adsorbent in Removing Chromium and Nickel fromdye effluent. Am. Chem. Sci. J. 2(1): 12-24.

Langmuir D (1997). Aqueous Environmental Chemistry, Pren- tice-Hall, Inc., New Jersey.

Lokhande, RS; Pravin, US; Deepali, SP (2011). Study on Physico-Chemical Parameters of Waste Water Effluents from Taloja Industrial Area of Mumbai, India. Int. J. Ecosys. 1(1): 1-9

Qadeer, R; Akhtar, S (2005). Kinetics study of lead ion adsorption on activated carbon. Turk. J. Chem. 29: 95-99.

Wilcox LV (1955). Classification and Use of Irrigation Waters. US Dept. of Agricultural Science, Grc. 